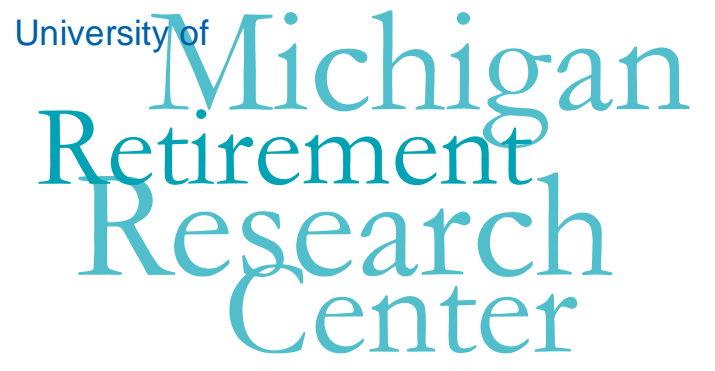

Working Paper WP 2011-255

\title{
The Effects of the Financial Crisis on Actual and Anticipated Consumption
}

\author{
Michael D. Hurd and Susann Rohwedder
}

\begin{tabular}{|l|l|}
\hline $\mathrm{M}$ & $\mathrm{R}$ \\
\hline $\mathrm{R}$ & $\mathrm{C}$ \\
\hline
\end{tabular}

Project \#: UM11-10 



\title{
The Effects of the Financial Crisis on Actual and Anticipated Consumption
}

\author{
Michael D. Hurd \\ RAND and NBER \\ Susann Rohwedder \\ RAND
}

October 2011

\author{
Michigan Retirement Research Center \\ University of Michigan \\ P.O. Box 1248 \\ Ann Arbor, MI 48104 \\ http://www.mrrc.isr.umich.edu \\ (734) 615-0422
}

\section{Acknowledgments}

This work was supported by a grant from the Social Security Administration through the Michigan Retirement Research Center (Grant \# RRC08098401-03-00). The findings and conclusions expressed are solely those of the author and do not represent the views of the Social Security Administration, any agency of the Federal government, or the Michigan Retirement Research Center.

\section{Regents of the University of Michigan}

Julia Donovan Darrow, Ann Arbor; Laurence B. Deitch, Bingham Farms; Denise Ilitch, Bingham Farms; Olivia P. Maynard, Goodrich; Andrea Fischer Newman, Ann Arbor; Andrew C. Richner, Grosse Pointe Park; S. Martin Taylor, Gross Pointe Farms; Katherine E. White, Ann Arbor; Mary Sue Coleman, ex officio 


\title{
The Effects of the Financial Crisis on Actual and Anticipated Consumption
}

\begin{abstract}
We studied how households adjust their spending in response to the financial crisis. Based on five waves of data from the Consumption and Activities Mail Survey, we quantified the reduction in total consumption and in specific categories of consumption in the older population at large and by stock ownership, both as a proxy for wealth and to test assumptions about whether stock ownership was associated with different responses. In particular, we compared consumption changes between 2007 and 2009 with consumption changes over prior years. We used panel data on anticipated changes in spending at retirement to quantify the effects of the financial crisis on well-being in retirement via a difference-in-differences approach.
\end{abstract}

\section{Authors' Acknowledgements}

This work was supported by a grant from the Social Security Administration through the Michigan Retirement Research Center (Grant UM11-10). The findings and conclusions expressed are solely those of the authors and do not represent the views of the Social Security Administration, any agency of the Federal government, or the Michigan Retirement Research Center. Joanna Carroll provided excellent programming assistance. 


\section{Introduction}

The recession that has been associated with the recent financial crisis officially started in December 2007 and ended in June 2009. According to survey responses in the American Life Panel (ALP), about 75 percent of households reported reducing spending because of the financial crisis in the months following the collapse of the stock market. Although an important indicator of behavior, this figure does not tell us the magnitude of the reduction. However, the size of the reduction in response to economic shocks is of great interest to both economists and policy makers: It conveys the extent to which households are able to smooth their consumption and with that maintain their economic wellbeing when experiencing economic shocks. If consumption smoothing is limited and households reduce consumption markedly, this response will contribute to contractions in the overall economy, which in times of a recession could lead to a downward spiral in economic activity in the U.S.

According to economic theory, the size of the consumption response to a shock depends on the degree to which households are insured against such shocks and also whether the economic shock is permanent. If shocks to income were fully insured, then households would be able to smooth their consumption completely. However, some types of insurance, such as unemployment benefits do not replace 100 percent of earnings. In the absence of complete insurance, households need to find ways of buffering such shocks. One possibility is self-insurance, that is, households could set aside some money in healthier times in order to be able to smooth the effect of economic shocks. In this scenario, households would be able to distribute the effect of the shock over a longer period of time, but to the extent that the shock is permanent, they still would need to re-optimize their consumption to adjust to the revised level of lifetime resources. If a household's liquidity is constrained, the household's ability to self-insure is limited. Another factor to consider is that households might desire to adjust their spending in response to an economic shock immediately, but for certain categories of spending, such adjustment may not be possible. This issue is particularly relevant for durable spending categories, such as 
automobiles or major household appliances, where the consumption services are distributed over a longer period of time, although the payment for those consumption services tends to occur at the time of purchase (except when financing is used). Even some nondurable categories of spending may be difficult to adjust quickly. Examples would include anything that requires a contract of a certain duration, like those that are customary for telephone or cable services, or insurance coverage.

The question of consumption smoothing in response to economic shocks is challenging to investigate empirically for at least two important reasons. First, finding sizeable changes in households' economic circumstances that are not anticipated is difficult. For example, changes in the stock market may be in part anticipated, especially in times when the stock market has been moving in mostly one direction. Second, very few data sources in the United States allow total household spending to be tracked over time. The Consumer Expenditure Survey (CEX) collects a comprehensive set of measures of household spending, but the data are cross-sectional. Longitudinal data sets that would allow households to be followed over time tend to include only partial measures of spending, if any. As a result, several studies have attempted to identify the effect of interest by focusing on food spending, for lack of a more comprehensive measure. For example, Gruber (1997) used food spending in the Panel Study of Income Dynamics (PSID) (1968-1987) to estimate the effect of public unemployment insurance (UI) benefits on consumption smoothing. He found that those who received generous UI benefits experienced little change in consumption during and after a period of unemployment. Those with no UI benefits experienced a drastic reduction (approximately 22 percent) in consumption. UI benefits seem to have a significant effect on consumption smoothing, especially among those who do not anticipate the unemployment shock. There appear to be no differential long-term effects of unemployment on consumption by level of UI entitlement, but eligibility for such benefits does seem to crowd out private savings that would serve as a buffer in the event of unemployment shocks. 
Using data from both the HRS and PSID, Stephens (2004) found that unemployment was associated with a reduction of approximately 16 percent in food spending. Browning and Crossley (2009) used Canadian data that covered the period from 1993 to 1995 and recorded a fairly comprehensive measure of household spending. However, the sample was restricted to those who experienced unemployment. Their empirical results suggest that among households with no liquid assets, total household expenditure is sensitive to the level of unemployment benefits. In particular, expenditures on clothing are more sensitive to cuts in benefits than are expenditures on food.

In this study, we used data from five waves of the Consumption and Activities Mail Survey (CAMS), which is a supplement to the Health and Retirement Study (HRS). CAMS collects longitudinal data on total household spending every two years from a sample that is representative of the U.S. population over the age of 50 . We compared consumption changes between 2007 and 2009 -the period that spans the onset and trough of the financial crisis-with consumption changes over prior years (2001-2007). This comparison allows us to distinguish changes in consumption that are attributable to the financial crisis from changes in spending that would ordinarily occur among the age groups that we study. In our analyses, we stratified by stock ownership and by whether the respondent experienced unemployment to assess how the spending changes differed among those particularly affected by the financial crisis compared to the rest of the population.

Because of the detailed information on spending available in the CAMS data, we were able to go beyond analyzing the changes in total spending and provide a detailed account of the categories of spending that households tended to adjust more than others, and how this outcome varied by age or by stock ownership. We stratified our analysis by stock ownership as a way to identify the spending response among households who suffered unusually large losses in their assets portfolio, compared to households that were less affected. 
For households comprising individuals who are not yet retired, one possible means of adjustment might be to postpone some spending reductions by scaling back their expected living standard in retirement. In order to assess whether this mechanism appears to be empirically important, we used panel data on anticipated changes in spending at retirement to quantify the effects of the financial crisis on well-being in retirement via a difference-in-differences approach.

\section{Data}

The data for this study come from the HRS, a multipurpose, longitudinal household survey that provides rich data representing the U.S. population over the age of 50 . The HRS sample comprises approximately 20,000 persons and 13,000 households. Since its inception in 1992, the HRS has surveyed age-eligible respondents and their spouses every two years (even-numbered years).

In 2001, the HRS added a supplemental survey eliciting details of household spending, the CAMS. The CAMS is collected every two years (odd-numbered years) in the year between the core HRS interviews. The CAMS sample consists of some 5,000 randomly selected HRS households, which provide information on some 38 categories of household spending, designed to measure total household spending over the preceding 12 months. For couples, the respondent to the survey is chosen at random and encouraged to solicit help from other household members in completing the questions about household spending. The first wave of CAMS was conducted in October 2001. The spending data can be linked to the rich background information that respondents provide in the HRS core interviews. Rates of item nonresponse are very low (mostly single-digit), and CAMS spending totals aggregate closely to those in the CEX (Hurd and Rohwedder, 2009). In this study, we used five waves of CAMS, spanning the period from 2001 through 2009. 


\section{Household Spending During the Great Recession Compared to Pre-Recession Spending}

Officially the Great Recession started in December of 2007 and lasted through June 2009. Since then the stock market has recovered somewhat, but neither the unemployment rate nor the housing market have shown noticeable signs of recovery since then. Because CAMS elicits spending in the 12 months preceding the interview, the 2007 CAMS interview fielded in October measured total household spending prior to the recession, and the 2009 CAMS interview, also fielded in October, measured total household spending during the trough of the recession. However, the changes in spending observed over that period cannot be directly attributed to the financial crisis. Household spending changes for any number of reasons, including grown children leaving the household, retirement, or changes with age due to increasing mortality risk, to name but a few. Therefore, we calculated the changes in spending between 2007 and 2009 that were in excess of those observed in normal (non-recession) times. We used the two-year transitions in spending observed in CAMS between 2001 and 2007 as our measure of spending changes in "normal times" and pooled the data from these three transitions prior to the recession to reduce observation error.

Classification by stock ownership focuses on stock holdings outside of retirement accounts. Classification of unemployment was determined from information on the respondent's labor force status at the time of the CAMS interview (i.e., in the fall of the CAMS interview year).

Table 1 shows the comparisons of two-year transitions in total spending for households where the respondent is age 50 to $65 .{ }^{1}$ Prior to the recession, spending averaged over the three initial waves of the three two-year transitions was $\$ 41.6$ thousand and it averaged $\$ 40.4$ thousand in the following wave. Thus, spending declined in the two-year panel data over the period 2001-2007 by 2.75 percent or about 1.4 percent per year. When we stratified respondents by stock ownership in the initial wave, we

\footnotetext{
${ }^{1}$ We focus on this age group so as to compare the responses to stock market shocks with responses to unemployment. Unemployment is not very relevant for the population 65 or older.
} 
found that stock owners had considerably higher spending than non-owners, as would be expected based on their greater economic resources both in terms of income and wealth. ${ }^{2}$ Furthermore, the decline in spending was entirely attributable to a reduction in spending in those households that did not hold stocks outside of retirement accounts: Among those households, spending declined by 4.6 percent over two years or about 2.3 percent per year.

Over the two years beginning in 2007 and ending in 2009, spending declined by almost 10 percent, which we suppose is mostly due to the financial crisis and Great Recession. A differences-indifferences comparison suggests that the excess decline associated with the financial crisis and Great Recession was 7 percent $(-9.76-(-2.75))$. However, a differences-in-differences comparison conducted by stock ownership suggests that among stock owners, the excess was 9.2 percent, whereas it was just 5.4 percent among non-owners. Thus, results of this differences-in-differences comparison suggest that for stock owners the excess reduction in spending associated with the economic crisis was 3.8 percentage points $(9.2-5.4)$ larger than among those not owning stocks.

\section{Household-level changes}

After drawing comparisons based on population-level statistics, we now turn to changes observed at the household level. Because of observation error on spending, mean values of the ratio of spending at

wave $t+1$ to spending at wave $t, \frac{s_{t+1}}{s_{t}}$, can be substantially upward biased. Therefore, we present median values of this household-level ratio (Table 2). As before, we pooled observations for the three

\footnotetext{
${ }^{2}$ Stratification by stock ownership is based on whether the household holds stocks outside of retirement accounts. Data on whether households hold stock inside of retirement accounts is not taken into account in this classification, implying that those not holding stocks outside of retirement accounts may or may not hold stocks inside their retirement accounts. Similarly, the group of households holding stocks outside of their retirement accounts includes some that do and some that do not hold stocks inside of their retirement accounts.
} 
transitions over the period 2001-2007. For all households, the median of $\frac{s_{t+1}}{s_{t}}$ was 0.977 , indicating a median two-year rate of spending reductions of 2.3 percent. The median reduction in spending was zero among households owning stock and 3.4 percent among households not owning stock. For the period 2007-2009, the median rates of spending reductions were substantially larger: 10.4 percent among stock owners and 7.4 percent among non-owners. Based on a differences-in-differences method, the rate of spending reductions associated with the Great Recession was substantially higher among stock owners than non-owners (about 6.2 percentage points higher (10.2-4.0)), suggesting that stock market losses contributed to the spending reductions.

\section{Assessing spending after controlling for household wealth. A potentially important} confounding factor in the statistics we have presented so far is that stockowners tend to have much higher wealth and income than those households not holding stocks. To account for this potential bias, we performed regressions of spending change, controlling for household wealth (Table 3).

In these regressions, the reference group is the initial wave 2001,2003 , or 2005 , not a stock owner, and wealth in the first quartile. The median regression and the ordinary least squares (OLS) give similar results except for the constant term, which is due to the difference in the specification of the left-hand variable (median ratio vs. the log of the mean ratio). ${ }^{3}$ Relative to the earlier waves, spending between 2007 and 2009 (wave 4 to wave 5) declined by about 2 percent, as shown on the wave 4 indicator. Spending by stock owners increased wave to wave by 2.6 percent (median regression) more than spending by households not owning stock. But over the period 2007-2009, spending by stockowners decreased by 4.3 percent more. These results are qualitatively the same and quantitatively

\footnotetext{
${ }^{3}$ The left-hand variable is the spending ratio in the case of median regression and the log spending ratio in the case of OLS. The spending ratio has large outliers that tend to dominate the OLS estimation: the maximum value of the spending ratio is 581.0 , and even with a $2 \%$ trim it is 9.5 . The influence of outliers is reduced in the log specification.
} 
similar to those derived from population means. For example, the additional decline from 2007 to 2009 attributed to holding stocks is 3.8 percent in Table 1, 4.3 percent from the median regression in Table 2, and 4.1 percent from the OLS regression. Because this spending decline includes declines by households with small holdings of stocks, it is likely that some larger holders had much greater declines.

Summary of changes in total spending We have four measures of the reduction in spending associated with the 2007 and 2009 waves and with stock ownership: comparisons of population means (Table 1); comparisons of the medians of household-level changes (Table 2); and comparisons of means and medians based on household-level data, which controls for wealth quartiles (Table 3). These results are summarized in Table 4. According to these measures spending declined by 3.5 percent to 7.0 percent more between 2007 and 2009 than between 2001 and 2007. We interpret this difference to be the effect of the recession on spending. The decline in spending by stock owners from 2007 to 2009 was substantially greater compared with the earlier period than the decline in spending by non-owners. The estimated excess ranged from 3.8 percent to 6.2 percent. We interpret these differences to indicate a reduction in spending that resulted from losses in the stock market and possibly reduced expectations by stock owners about future stock market gains.

\section{Spending Changes by Spending Category}

Households are likely to adjust spending categories differentially in response to economic shocks. Spending on necessities such as food consumed at home is likely to be reduced less than spending on categories that are optional, like dining out or home improvements. In addition, households may face some constraints that make it difficult to adjust some spending categories quickly. For example, reducing the consumption of housing services involves a move, possibly even the sale of a house. This action might take not only some time, but also involve considerable transaction 
costs. Reducing the consumption of other durable items like a car or a refrigerator would involve similar constraints. Even adjusting the amount spent on telephone service or insurance coverage might take some time, because of the frequent requirements to commit to a contract for a fixed duration.

The CAMS survey provides detailed information on the categories of spending that constitute the total of household spending. Tables 5, 6, and 7 show how the observed changes in total spending are distributed across the various categories of spending. We consider the following broad categories of spending:

1. Big ticket items (refrigerator, washer or dryer, dishwasher, television, personal computer, automobile purchases)

2. Food and beverages

3. Dining out

4. Clothing

5. Utilities (electricity, water, heating, telecommunications [phone, cable, Internet])

$6 . \quad$ Out-of-Pocket Health (health insurance premiums, drugs [prescription and over-thecounter), health care services, medical supplies)

7. Leisure (trips and vacations, hobbies, sports, tickets and other entertainment)

8. Donations and gifts (contributions, cash and gifts to people outside the household)

9. Household supplies and services (housekeeping supplies and services, gardening supplies and services)

10. Housing (mortgage, rent, home repair, home furnishings, home owners' and renters' insurance)

11. Transportation (car payment, vehicle insurance, vehicle maintenance)

In view of the timing of the CAMS survey, spanning the onset of the financial crisis (October 2007 and October 2009), we suspect that the two-year transitions that we analyzed capture all short- and medium-term adjustments to spending, but they may not fully capture longer-term adjustments such as adjustments to housing services.

We present comparisons stratified by stock ownership in addition to those for the entire population. The last three columns in Tables 5, 6, and 7, labeled differences-in-differences, give the 
percentage points of excess spending change attributable to the financial crisis by stock ownership (no/yes) and for the entire population.

All ages. Looking at spending by category for all ages (Table 5), the greatest declines in spending in response to the financial crisis were on big ticket items (-7.3 percentage points), dining out (-15.9 percentage points), and housing (-8.5 percentage points). The decline in spending on durable goods such as big ticket items is understandable as many such purchases can be deferred. Likewise, households can substitute food eaten at home for more costly meals eaten away from home; as expected, purchases of food and beverages to be consumed at home showed a much smaller decline as a result. The decline in spending on housing was mainly due to deferred home improvement and maintenance and foregone purchases of home furnishings.

Among the categories that saw the smallest declines or saw actual gains in spending were outof-pocket health expenses and donations and gifts. The rise in spending on health care may be a price effect, that is, a reflection of the fact that medical inflation is higher than the Consumer Price Index, whereas the rise in spending on donations and gifts likely reflects money spent to help children, grandchildren, or other relatives in difficult economic times (see Rohwedder, 2009).

Differences by stock ownership. We then compared changes in spending by stock owners and nonowners, proposing that stock owners would reduce their spending more to cover their greater losses in economic resources, and that these reductions would be reflected in spending categories where spending was flexible or could be deferred (Table 5, columns 7 and 8). As expected, spending declined more for stock owners than for non-owners (-6.5\% vs. $-3.0 \%)$ in response to the financial crisis. Assessing differences in changes in spending between owners and non-owners by category, among the largest differences was in spending on big ticket items, purchases that often can be deferred. Additional 
categories with large differences by stock ownership were household supplies and services and housing. Owners reduced their expenditures less than non-owners in the categories of transportation and dining out. Spending on donations and gifts actually rose more among non-owners than among owners.

Comparing "All" spending changes by age. We then compared changes in spending by those 66 and over (last column Table 7) with that of persons 50-65 (last column Table 6). We posited that the older population would be less affected by the financial crisis in accordance with the findings in Hurd and Rohwedder (2010). This is in part because unemployment is less of a concern in this age group and also Social Security benefits - which were unaffected by the crisis - provide the most important source of income for most households in this age group. We also hypothesized that older adults' greater amount of free time would allow an easier transition to home production (although unemployment among the younger population could serve the same purpose).

For all individuals 66 and over (both stock owners and non-owners), overall spending declines were smaller than for those 50 to 65 (-2.4 vs. -7.0). Notably greater declines in spending among those 66 and over were seen in four categories. Spending on food eaten at home saw a greater decline, possibly due to more efficient shopping. Spending on clothing also declined more among the older population in response to the financial crisis. Perhaps the younger population could not reduce clothing as much because of the need for work clothes. Spending on household supplies and services also declined more in the older age group, which may be due to them beginning to use their leisure time to perform more chores themselves than before (home production). The same explanation may apply to the reduction in housing expenses that is in part driven by reduced spending on home maintenance and improvements. Spending on donations and gifts increased more in the older age group than in the younger group $(+12 \%$ vs. $-2.0 \%)$, possibly because of the need to help support younger family members. 
We then compared the older age group to the younger age group by stock ownership. Among older stock owners, spending declines were greater than among older non-owners. However, compared with stock owners in the 50-65 age group, spending by stock owners 66 and over was affected by about the same extent: in both age bands, owners reduced spending by about 3.7 percent more than non-owners. Comparing spending in categories between owners and non-owners, spending on durable goods by owners declined 9.6 percent, compared with an increase in spending of 9.1 percent for non-owners (for a total difference of 18.7 percent). In the younger group the difference between owners and nonowners was just 2.2 percent. Older owners also had much greater declines in spending on household supplies and services and on housing than non-owners and smaller increases in donations and gifts (19.7 percent increase for non-owners vs. 6.3 percent for owners).

\section{Unemployment and spending change}

Between the onset of the Great Recession in December of 2007 and the official end of the economic crisis in June 2009, the U.S. unemployment rate doubled, increasing from 4.7 percent in November 2007 to 9.5 percent (Bureau of Labor Statistics based on Current Population Survey). Similar to large losses in the stock market, a job loss is an economic shock that tends to be unanticipated. To examine the response of spending to unemployment and whether this response changed during the financial crisis, we considered employment transitions between two adjacent waves of CAMS. For the period 2001 to 2007 (three transitions), we pooled observations and calculated transition rates and associated levels and changes in spending. We consider these transitions "normal" in the sense that they occurred in the period prior to the Great Recession. We compared them to employment transitions from 2007 to 2009 where spending changes may have differed. In order not to confound spending changes in response to unemployment with those associated with retirement, we limited the 
sample to those who were steadily employed or unemployed in both the initial wave and the following wave. $^{4}$

Table 8 shows that the average unemployment rate among CAMS respondents in the two-year panels was 4.8 percent in the years 2001,2003 , and 2005 , and 5.6 percent in the following wave. Among those employed in the initial wave, 95.5 percent were employed in the following wave. The persistence of unemployment is illustrated by the low transition rate from unemployment to employment, just 73 percent. In 2007 , at the beginning of the financial crisis, the unemployment rate in the 2007 to 2009 panel was 4.7 percent among CAMS respondents (Table 9), increasing to 8.4 percent during the two years. The transition rate out of unemployment was not substantially changed from the earlier transitions, but the transition rate from employment to unemployment increased to 7.6 percent.

Table 10 shows spending among panel respondents who reported being employed in an initial wave and who were either employed or unemployed in the following wave. Spending was averaged over three initial waves (spending in wave $t$ ) and over three subsequent waves (spending in wave $t+1$ ). Thus, those who became unemployed in a subsequent wave had spent an average of $\$ 38,700$ in the previous wave when they were employed. Those who remained employed had spent an average of $\$ 45,100$ in the initial wave, illustrating the well-known empirical regularity that those who become unemployed come from the lower part of the income distribution prior to their unemployment. The decline in spending that accompanied unemployment was just 3.6 percent, much smaller than we have found in high-frequency data collected in the ALP. This difference may be partly attributable to the small sample size: the change in spending accompanying unemployment is based on just 68 observations.

\footnotetext{
${ }^{4}$ In CAMS, these states are self-reported. The CAMS employment and unemployment rates differ from national averages because CAMS does not require any job search actions to be classified as unemployed as is required in the CPS. Unemployment includes "laid off."
} 
We compared these changes in spending between 2001 and 2007 with changes between 2007 and 2009. Table 11 shows spending by those who were employed in 2007 and who were either employed or unemployed in 2009. The later results show two notable differences from the results based on the earlier periods. First, initial spending by those who eventually became unemployed was about the same as spending by those who did not become unemployed, illustrating that unemployment in the Great Recession tended to affect individuals of all income levels equally. Second, the recent declines in spending were much greater than in earlier periods: a 19 percent decline among those who became unemployed and 10 percent among those who remained employed. The spending response to unemployment appears to have been substantially larger during the financial crisis (by about 15 percentage points according to Tables 10 and 11), but we caution that the sample size was too small to draw definite conclusions.

In Table 12 we present regression results to verify whether the differential spending response to unemployment during the financial crisis was statistically significant. The sample was restricted to those aged 50-65 who were employed in the initial wave of the transition, pooling all pre-crisis transitions and the transition spanning the onset of the crisis. The left hand variable is the ratio of spending in wave $t$ to spending in wave $t+1$, calculated at the household level. The right hand variables include an indicator for wave 4, which takes the value 1 if the transition involves the onset of the financial crisis, another indicator for whether the respondent became unemployed, and an interaction term between becoming unemployed and the wave 4 indicator that captures the differential spending response to unemployment during the financial crisis. Indeed the only statistically significant coefficient is the one associated with the wave 4 indicator, implying that among those employed at the initial wave, the average spending reduction associated with the financial crisis was 6.2 percent above and beyond spending reductions associated with unemployment in normal times. The effects of becoming 
unemployed, either in normal times or during the financial crisis, were not precisely estimated because the sample sizes associated with unemployment were too small. ${ }^{5}$

\section{Anticipated changes in spending at retirement and how they changed in response to the Great \\ Recession}

Economic theory suggests that households should immediately adjust their spending to economic shocks, provided that these shocks are considered permanent. However, when economic shocks affect lifetime resources as in the Great Recession, some households may be slow to adjust consumption. Furthermore, their reduced economic resources may lead them to alter their desired living standards in retirement relative to their standard of living before retirement. For example, prior to becoming unemployed, an individual may have anticipated traveling during retirement. However, if that same individual became unemployed in his or her 50s, he might reduce his expectations about traveling and so reduced expected spending in retirement. To assess whether such adjustments were empirically important, we used data from the five waves of CAMS on anticipated changes in spending at retirement. In each wave of CAMS, respondents who classify themselves as not retired are asked whether they anticipate their spending will change at retirement and if so, by how much.

Figure 1 shows the average percentage of respondents who anticipated a reduction in spending at retirement. CAMS waves 2001 to 2007 were pooled to establish the pattern of responses in "normal" times and compared with responses in the 2009 survey, which was fielded shortly after the low point of the Great Recession. We predicted that more respondents would anticipate a reduction in spending at retirement in 2009 than in prior waves. The data bore this prediction out, although the difference was

\footnotetext{
${ }^{5}$ Once we include HRS 2010 data in our analysis we will be able to improve our measures of whether and to what extent households have suffered economic losses during the financial crisis.
} 
small, 72.5 percent vs. 69.4 percent. Of greater interest was the change in the age pattern. Prior to 2009, the percent anticipating a decline was greatest at ages 58 to 59 and then fell by about 12 percentage points by ages 64 to 65 . In 2009, the percentage anticipating a decline increased from 71 percent to 76 percent over those same age ranges. Apparently, the financial crisis and subsequent Great Recession disproportionately affected those closest to retirement, either through a direct effect on financial resources or an indirect effect through increased uncertainty.

Figure 2 shows the average anticipated spending change at retirement. The average increased from a 21 percent drop to a 23 percent drop. With the exception of the change at ages 64-65, the age pattern was about the same in 2001 to 2007 . We conclude that among those very close to retirement, the Great Recession induced a substantially greater number to anticipate a spending reduction at retirement but that the magnitude of the reduction did not change in an important way.

\section{Summary and Conclusions}

The financial crisis and the subsequent Great Recession directly impacted households via losses in the stock market, losses in home equity, and unemployment. To the extent that these losses were unanticipated, households should have reduced spending. However, in addition, households undoubtedly altered their expectations of their future economic positions, which according to the lifecycle model, would have an additional depressing effect on spending. Indeed, we find that the estimated reductions in spending over the time period 2007 to 2009 were between 3.6 to 7.0 percentage points greater among 50 to 65 year-olds than over earlier two-year time periods. We interpret this reduction as being attributable to the Great Recession.

Our method of ascertaining whether some of the estimated reduction in spending was attributable to losses in the stock market was to compare changes in spending by stock owners with 
changes in spending by non-owners both in the periods from 2001 to 2007 and 2007 to 2009 . We found that owners aged 50 to 65 reduced spending by an additional 3.8 to 6.2 percentage points (depending on specification) compared with non-owners from the same age band over the 2007 to 2009 period. While suggestive of a substantial wealth effect, it is premature to come to such a conclusion. Because stock owners are more likely to own houses than non-owners, they are more likely to have experienced losses in house value. Thus, some of the decline in spending by stock owners could be due to a loss of housing wealth. Stock owners are more likely to follow the stock market and therefore have reduced expectations about the future course of the stock market. Such altered expectations should lead to a reduction in spending. However, with respect to unemployment and expectations of unemployment, there is no reason to think that stock owners became more pessimistic about their employment prospects than non-owners.

Our hypothesis about unemployment was that spending would be reduced due to unemployment, but that the reduction would be greater between 2007 and 2009 than between earlier two-year periods because of the actual difficulty of re-employment and because of reduced expectations of re-employment. While spending did decline substantially among households that transited from employed in 2007 to unemployed in 2009 (by 19\%), it declined by $10 \%$ among households that were employed in both years. Possibly because of sample size, any additional effect of unemployment attributed to the Great Recession was not statistically significant.

We conclude that the Great Recession had a substantial effect on spending, and that stock owners reduced their spending more than did non-owners. However, additional research and possibly additional data will be required to disaggregate the fraction of the changes that is attributable to changes in stock prices, to changes in housing prices, and to changes in unemployment and expectations. 


\section{References}

Browning, M., T. F. Crossley, et al. (2009). Shocks, Stocks and Socks: Smoothing Consumption Over a Temporary Income Loss, Journal of the European Economic Association, 7(6): 1169-1192.

Gruber, J. (1997). "The consumption smoothing benefits of unemployment insurance." The American Economic Review: 192-205.

Hurd, M. D. and S. Rohwedder. 2010. "The Effects of the Economic Crisis on the Older Population," Michigan Retirement Research Center Working Paper 2010-231.

Hurd, M. D. and S. Rohwedder. 2009. "Methodological Innovations in Collecting Spending Data: The HRS Consumption and Activities Mail Survey." Fiscal Studies 30(3/4):435-459.

Rohwedder, S. 2009. "Helping Each Other in Times of Need - Financial Help as a Means of Coping with the Economic Crisis," RAND Occasional Paper (OP-269).

Stephens Jr, M. (2004). "Job loss expectations, realizations, and household consumption behavior." Review of Economics and Statistics 86(1): 253-269. 


\section{Tables}

Table 1. Total spending (2003 dollars) in initial wave ( $t$ ), in following wave $(t+1)$ and change in spending by direct stock ownership in initial wave. Two-year panels. 2001, 2003 and 2005 pooled and two-year panel 2007-2009. Ages 50-65

\begin{tabular}{lcrrrrr}
\hline & \multicolumn{3}{c}{ Initial waves 2001, 2003 \& 2005 } & \multicolumn{3}{c}{ Initial wave 2007 } \\
& \multicolumn{3}{c}{ stock ownership } & \multicolumn{3}{c}{ stock ownership } \\
\cline { 2 - 7 } & No & Yes & All & No & Yes & All \\
\cline { 2 - 7 } Wave t & 36,003 & 52,650 & 41,590 & 34,645 & 52,724 & 39,708 \\
Wave t+1 & 34,358 & 52,501 & 40,446 & 31,204 & 47,738 & 35,834 \\
Change (\%) & -4.57 & -0.28 & -2.75 & -9.93 & -9.46 & -9.76 \\
& & & & & & \\
\hline
\end{tabular}

Note: Pre-recession spending is averaged over three two-year panels. The changes 2001-2007 are almost exactly the same when calculated as the average of three changes rather than the change in average spending. The average rate of stock owning in the initial waves was $34.1 \%$ in $2001,34.9 \%$ in $2003,31.6 \%$ in 2005 and $28.0 \%$ in 2007 . Stock ownership does not include stocks held in retirement accounts.

Table 2. Median of ratio of total spending in wave $t+1$ to spending in wave $t$, age 50-65

\begin{tabular}{lccc}
\hline & \multicolumn{3}{c}{ stock ownership in initial wave } \\
& No & Yes & All \\
$2001-2007$ & 0.966 & 0.998 & 0.977 \\
$2007-2009$ & 0.926 & 0.896 & 0.919 \\
\cline { 2 - 4 } Difference & -0.040 & -0.102 & -0.058 \\
& & & \\
\hline
\end{tabular}

Note: $\mathrm{N}=3,656$ for $2001-2007 ; \mathrm{N}=1,078$ for $2007-2009$. 
Table 3. Regression of ratio of spending in wave $t$ to spending in wave $t+1$.

two-year panels, 2001-2009

\begin{tabular}{lrccccc}
\hline & \multicolumn{3}{c}{$\begin{array}{c}\text { Median regression of } \\
\text { spending ratio }\end{array}$} & \multicolumn{3}{c}{$\begin{array}{c}\text { Mean regression of log } \\
\text { spending ratio. 2\% trim. }\end{array}$} \\
& Coefficient & $\begin{array}{c}\text { Standard } \\
\text { error }\end{array}$ & t-statistic & Coefficient & $\begin{array}{r}\text { Standard } \\
\text { error }\end{array}$ & t-statistic \\
Wave 4 indicator & -0.022 & 0.011 & -1.91 & -0.020 & 0.012 & -1.61 \\
Own stock initial wave & 0.026 & 0.011 & 2.32 & 0.028 & 0.012 & 2.26 \\
Own stock wave 4 & -0.043 & 0.020 & -2.11 & -0.041 & 0.022 & -1.86 \\
Wealth quartile 2 & -0.008 & 0.012 & -0.67 & -0.021 & 0.013 & -1.68 \\
3 & -0.013 & 0.012 & -1.06 & -0.018 & 0.013 & -1.38 \\
4 & -0.006 & 0.013 & -0.48 & -0.014 & 0.015 & -0.98 \\
Constant & 0.959 & 0.009 & 110.19 & -0.031 & 0.010 & -3.26 \\
\hline
\end{tabular}

$\mathrm{N}$ for median regression: $12,030 . \mathrm{N}$ for trimmed mean regression: 11,291

Table 4. Summary of Results

\begin{tabular}{lrr}
\hline & & Stock owners compared with \\
& All & nonowners \\
\hline Ratio of mean spending & -7.0 & -3.8 \\
Median household change in spending & -5.8 & -6.2 \\
Median regression & -3.6 & -4.3 \\
Trimmed mean regression & -3.5 & -4.1 \\
\hline
\end{tabular}


Table 5. Percent changes in spending between wave $t$ and wave $t+1$, by stock ownership, and differentials in spending changes comparing pre-crisis spending changes to those covering the onset of the financial crisis. Age 50+.

\begin{tabular}{|c|c|c|c|c|c|c|c|c|c|}
\hline \multirow{3}{*}{$\begin{array}{l}\text { Spending } \\
\text { Category }\end{array}$} & \multicolumn{6}{|c|}{ Percent Changes in spending between wave $t$ and wave $t+1$} & \multirow{2}{*}{\multicolumn{3}{|c|}{$\begin{array}{l}\text { Differences-in-differences } \\
2007 \text { stock ownership }\end{array}$}} \\
\hline & \multicolumn{3}{|c|}{ 2001/03/05 stock ownership } & \multicolumn{3}{|c|}{2007 stock ownership } & & & \\
\hline & No & Yes & All & No & Yes & All & No & Yes & All \\
\hline Total spending & -6.1 & -2.8 & -4.6 & -9.1 & -9.4 & -9.2 & -3.0 & -6.5 & -4.6 \\
\hline Big ticket & -6.1 & 1.3 & -2.8 & -8.7 & -12.1 & -10.1 & -2.6 & -13.4 & -7.3 \\
\hline Non-durables & -4.9 & -1.7 & -3.5 & -8.2 & -8.3 & -8.2 & -3.3 & -6.6 & -4.8 \\
\hline Food\&beverages & -3.9 & -1.0 & -2.8 & -6.6 & -5.1 & -6.1 & -2.7 & -4.0 & -3.3 \\
\hline Dining out & -0.7 & -1.5 & -1.0 & -17.9 & -15.4 & -16.9 & -17.2 & -14.0 & -15.9 \\
\hline Clothing & -22.4 & -19.0 & -21.0 & -23.0 & -24.1 & -23.4 & -0.6 & -5.1 & -2.5 \\
\hline Utilities & 1.3 & 3.0 & 1.9 & 2.6 & 5.8 & 3.7 & 1.3 & 2.9 & 1.7 \\
\hline OOP health exp & -8.1 & -0.7 & -4.9 & -1.6 & 9.9 & 2.7 & 6.5 & 10.6 & 7.6 \\
\hline Leisure & -18.7 & -7.9 & -13.0 & -14.3 & -17.5 & -15.9 & 4.4 & -9.6 & -3.0 \\
\hline HH suppl\&svces* & -7.5 & 0.6 & -3.8 & -8.8 & -11.8 & -10.0 & -1.4 & -12.4 & -6.2 \\
\hline Housing** & -5.4 & 1.1 & -2.8 & -9.5 & -14.1 & -11.3 & -4.1 & -15.2 & -8.5 \\
\hline Transportation* & -13.9 & -12.8 & -13.5 & -18.0 & -14.6 & -16.9 & -4.1 & -1.9 & -3.4 \\
\hline Donations\&gifts & -12.8 & -11.5 & -12.1 & -0.4 & -8.9 & -4.8 & 12.4 & 2.6 & 7.3 \\
\hline
\end{tabular}

* Excludes 01-03 transition

**Excludes 01-03 and 03-05 transition

Table 6: Percent changes in spending between wave $t$ and wave $t+1$, by stock ownership, and differentials in spending changes comparing pre-crisis spending changes to those covering the onset of the financial crisis. Age 50-65.

\begin{tabular}{|c|c|c|c|c|c|c|c|c|c|}
\hline \multirow{3}{*}{$\begin{array}{l}\text { Spending } \\
\text { Category }\end{array}$} & \multicolumn{6}{|c|}{ Percent Changes in spending between wave $t$ and wave $t+1$} & \multirow{2}{*}{\multicolumn{3}{|c|}{$\begin{array}{l}\text { Differences-in-differences } \\
2007 \text { stock ownership }\end{array}$}} \\
\hline & \multicolumn{3}{|c|}{ 2001/03/05 stock ownership } & \multicolumn{3}{|c|}{2007 stock ownership } & & & \\
\hline & No & Yes & All & No & Yes & All & No & Yes & All \\
\hline Total spending & -4.6 & -0.3 & -2.8 & -9.9 & -9.5 & -9.8 & -5.4 & -9.2 & -7.0 \\
\hline Big ticket & -2.3 & 9.4 & 2.8 & -16.6 & -7.0 & -12.8 & -14.3 & -16.5 & -15.6 \\
\hline Non-durables & -3.4 & 0.1 & -1.9 & -9.4 & -6.3 & -8.3 & -6.0 & -6.4 & -6.4 \\
\hline Food\&beverages & -4.1 & -1.4 & -3.1 & -4.3 & 0.3 & -2.9 & -0.2 & 1.7 & 0.3 \\
\hline Dining out & -5.3 & 6.1 & -0.4 & -17.1 & -7.8 & -13.6 & -11.8 & -13.9 & -13.2 \\
\hline Clothing & -22.4 & -20.0 & -21.3 & -24.7 & -18.4 & -22.4 & -2.3 & 1.5 & -1.1 \\
\hline Utilities & 2.2 & 4.0 & 2.8 & 5.5 & 9.6 & 6.8 & 3.4 & 5.7 & 4.0 \\
\hline OOP health exp & -3.9 & 0.1 & -2.2 & -5.7 & 19.6 & 2.7 & -1.8 & 19.6 & 4.9 \\
\hline Leisure & -14.8 & -0.5 & -7.7 & -14.9 & -13.1 & -14.1 & -0.2 & -12.6 & -6.4 \\
\hline HH suppl\&svces* & -10.5 & 0.5 & -5.5 & -5.5 & -6.4 & -5.9 & 5.0 & -6.9 & -0.4 \\
\hline Housing** & -3.0 & -4.6 & -3.6 & -13.2 & -12.1 & -12.8 & -10.3 & -7.5 & -9.2 \\
\hline Transportation* & -12.9 & -12.3 & -12.6 & -15.8 & -16.1 & -15.9 & -2.9 & -3.7 & -3.3 \\
\hline Donations\&gifts & -9.7 & -7.1 & -8.4 & -8.5 & -12.9 & -10.4 & 1.2 & -5.8 & -2.0 \\
\hline
\end{tabular}

* Excludes 01-03 transition

**Excludes 01-03 and 03-05 transition 
Table 7: Percent changes in spending between wave $t$ and wave $t+1$, by stock ownership, and differentials in spending changes comparing pre-crisis spending changes to those covering the onset of the financial crisis. Age 66+.

\begin{tabular}{|c|c|c|c|c|c|c|c|c|c|}
\hline \multirow{3}{*}{$\begin{array}{l}\text { Spending } \\
\text { Category }\end{array}$} & \multicolumn{6}{|c|}{ Percent Changes in spending between wave $t$ and wave $t+1$} & \multirow{2}{*}{\multicolumn{3}{|c|}{$\begin{array}{l}\text { Differences-in-differences } \\
2007 \text { stock ownership }\end{array}$}} \\
\hline & \multicolumn{3}{|c|}{ 2001/03/05 stock ownership } & \multicolumn{3}{|c|}{2007 stock ownership } & & & \\
\hline & No & Yes & All & No & Yes & All & No & Yes & All \\
\hline Total spending & -7.8 & -4.9 & -6.4 & -8.5 & -9.3 & -8.8 & -0.7 & -4.4 & -2.4 \\
\hline Big ticket & -10.2 & -6.6 & -8.5 & -1.1 & -16.3 & -7.6 & 9.1 & -9.6 & 0.9 \\
\hline Non-durables & -6.5 & -3.2 & -5.0 & -7.3 & -9.5 & -8.2 & -0.8 & -6.4 & -3.2 \\
\hline Food\&beverages & -4.5 & -0.5 & -2.9 & -8.2 & -8.2 & -8.2 & -3.8 & -7.7 & -5.3 \\
\hline Dining out & 3.9 & -7.2 & -1.9 & -18.4 & -19.8 & -19.0 & -22.3 & -12.7 & -17.1 \\
\hline Clothing & -22.6 & -17.8 & -20.5 & -21.4 & -28.1 & -24.3 & 1.2 & -10.4 & -3.8 \\
\hline Utilities & 0.5 & 2.3 & 1.2 & 0.6 & 3.6 & 1.6 & 0.1 & 1.3 & 0.4 \\
\hline OOP health exp & -10.9 & -1.0 & -6.6 & 0.8 & 5.6 & 2.7 & 11.6 & 6.5 & 9.3 \\
\hline Leisure & -22.4 & -14.5 & -17.9 & -13.8 & -20.5 & -17.4 & 8.7 & -6.1 & 0.6 \\
\hline HH suppl\&svces* & -5.3 & 0.6 & -2.6 & -10.7 & -14.4 & -12.3 & -5.4 & -15.0 & -9.7 \\
\hline Housing** & -8.2 & 8.0 & -1.9 & -6.1 & -15.8 & -9.9 & 2.1 & -23.8 & -8.0 \\
\hline Transportation* & -15.5 & -13.4 & -14.7 & -20.3 & -13.4 & -17.9 & -4.8 & 0.0 & -3.2 \\
\hline Donations\&gifts & -15.2 & -13.7 & -14.3 & 4.5 & -7.5 & -2.2 & 19.7 & 6.3 & 12.1 \\
\hline
\end{tabular}

* Excludes 01-03 transition

**Excludes 01-03 and 03-05 transition 
Table 8. Employment and unemployment rates and transition rates, pooled two-year panel observations, 2001-2007, ages 50-65

\begin{tabular}{lrrrr}
\hline & & \multicolumn{3}{c}{ Wave t+1 rate } \\
\cline { 3 - 5 } Wave t status & Wave t rate & Unemployed & Employed & All \\
\hline Unemployed & 4.8 & 27.3 & 72.7 & 100.0 \\
Employed & 95.2 & 4.5 & 95.5 & 100.0 \\
All & 100.0 & 5.6 & 94.4 & 100.0 \\
\hline
\end{tabular}

Notes: $\mathrm{N}=1,601$

Table 9. Employment and unemployment rates and transition rates, pooled two-year panel observations, 2007-2009, ages 50-65

\begin{tabular}{lrrrr}
\hline & & \multicolumn{3}{c}{ Wave 2009 rate } \\
\cline { 3 - 5 } $\begin{array}{l}\text { Wave 2007 } \\
\text { status }\end{array}$ & $\begin{array}{l}\text { Wave 2007 } \\
\text { rate }\end{array}$ & Unemployed & Employed & All \\
\cline { 3 - 5 } Unemployed & 4.7 & 24.0 & 76.0 & 100.0 \\
Employed & 95.3 & 7.6 & 92.4 & 100.0 \\
All & 100.0 & 8.4 & 91.6 & 100.0 \\
\hline
\end{tabular}

Notes: $\mathrm{N}=536$ 
Table 10. Total spending (2003\$) among those employed in wave $t$ by employment status in wave $t+1$, pooled two-year panel observations 2001-2007, ages 50-65

\begin{tabular}{lrr}
\hline & \multicolumn{2}{c}{ employment status in wave $\mathrm{t}+1$} \\
& unemployed & employed \\
\cline { 2 - 3 } spending in wave $\mathrm{t}$ & 38717 & 45060 \\
spending in wave $\mathrm{t}+1$ & 37320 & 44797 \\
Percent change & -3.61 & -0.58 \\
$N$ & 68 & 1456 \\
\hline
\end{tabular}

Table 11. Total spending (2003 dollars) among those employed in wave 2007 by employment status in wave 2009, two-year panel observations, ages 50-65

\begin{tabular}{|c|c|c|}
\hline & \multicolumn{2}{|c|}{ employment status in 2009} \\
\hline & unemployed & employed \\
\hline spending in wave 2007 & 45036 & 44692 \\
\hline spending in wave 2009 & 36537 & 40276 \\
\hline Percent change & -18.87 & -9.88 \\
\hline$N$ & 39 & 472 \\
\hline
\end{tabular}

Table 12. Regression of ratio of spending in wave $t$ to spending in wave $t+1$. Two-year panels 20012009. Employed in initial wave and either employed or unemployed in subsequent wave. Ages 50-65

\begin{tabular}{lrrrrrr}
\hline & \multicolumn{3}{c}{$\begin{array}{c}\text { Median regression. } \\
\text { Spending ratio }\end{array}$} & \multicolumn{2}{c}{$\begin{array}{c}\text { Mean regression. } \\
\text { Log spending ratio. 2\% trim. }\end{array}$} \\
\cline { 2 - 7 } & Coefficient & $\begin{array}{c}\text { Standard } \\
\text { error }\end{array}$ & t-statistic & Coefficient & $\begin{array}{r}\text { Standard } \\
\text { error }\end{array}$ & t-statistic \\
\cline { 2 - 7 } Wave 4 indicator & -0.062 & 0.016 & -3.82 & -0.055 & 0.019 & -2.92 \\
Became unemployed & -0.065 & 0.041 & -1.60 & -0.026 & 0.048 & -0.55 \\
became unemployed wave 4-5 & 0.015 & 0.069 & 0.22 & -0.055 & 0.081 & -0.68 \\
Constant & 0.983 & 0.008 & 122.77 & -0.004 & 0.009 & -0.46 \\
\hline
\end{tabular}


Figures

Figure 1. Percent who anticipated a decline in spending

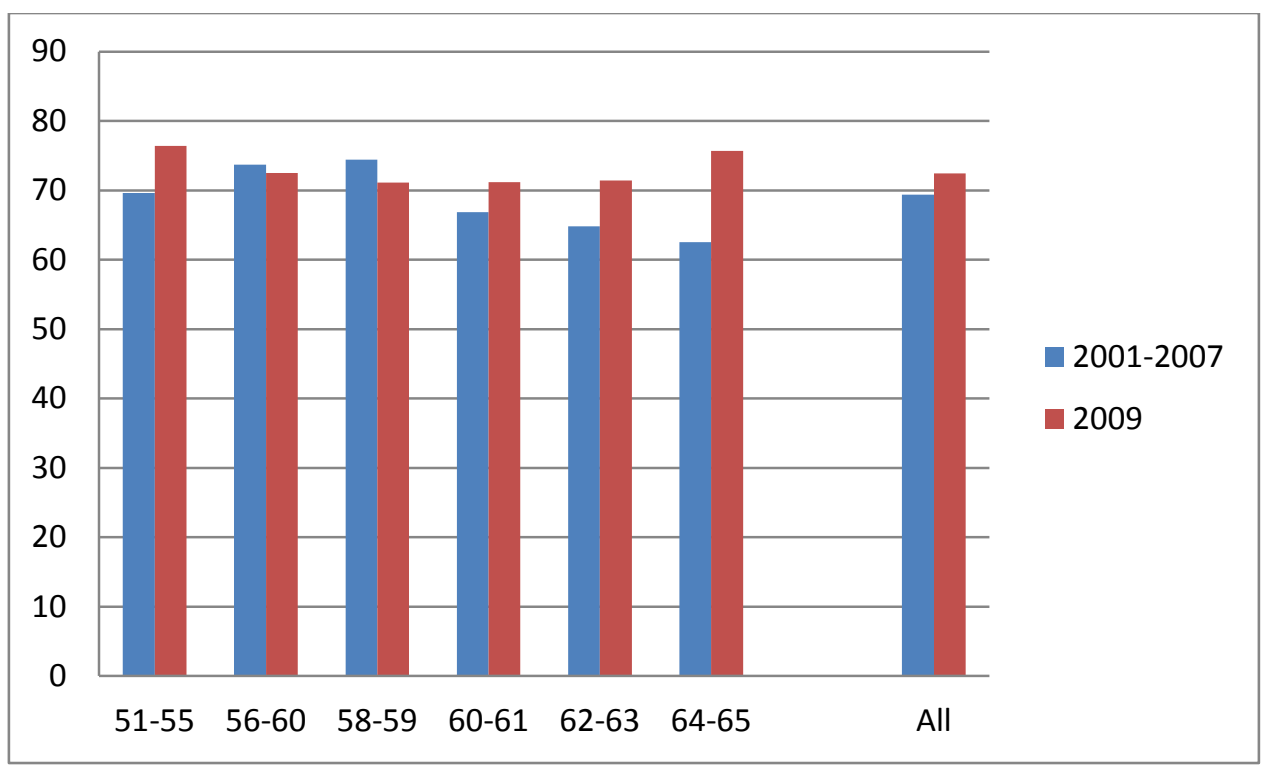

Figure 2. Anticipated change in spending (\%)

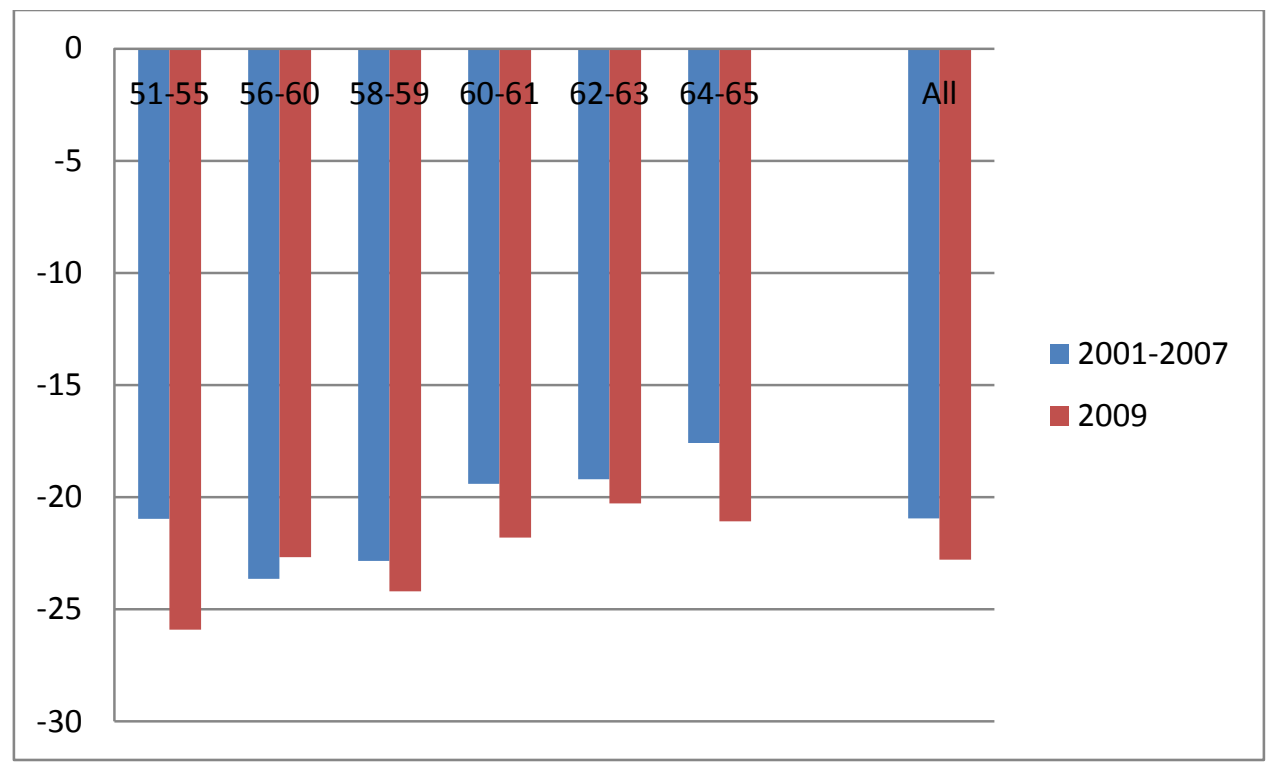

